ing is critical for the information transfer across the juxtaglomerular interstitial space. The results confirm the notion that adenosine generation is necessary for the vascular response. Furthermore, they strongly suggest that adenosine is formed in the extracellular space by nucleotide hydrolysis. While the data from Castrop et al. only directly invoke $5^{\prime}$-AMP as an adenosine precursor, it is not farfetched to assume that adenosine is the hydrolysis product of ATP and that its formation rate may well be modulated by varying levels of ATP. In this case, rather than being mediated by ATP or adenosine along alternative pathways, tubuloglomerular feedback may be the result of successive involvement of both ATP and adenosine. This may serve as a reminder that in long-standing scientific controversies, it is perhaps more the rule than the exception that both sides reflect part of the truth, and that the solution lies in combining these parts of the truth into a coherent picture.

Address correspondence to: Wilhelm Kriz, Department of Anatomy and Cell Biology, University of Heidelberg, Im Neuenheimer Feld 307, 69120 Heidelberg, Germany. Phone: 49-6221-54-8680; Fax: 49-6221-54-4951; E-mail: wilhelm.kriz@urz.uni-heidelberg.de.
1. Goormaghtigh, N. 1937. L'appareil neuro-myoartériel juxta-glomérulaire du rein: ses réactions en pathologie et ses rapports avec le tube urinifere. C. $R$. Seances Soc. Biol. Fil. 124:293-296.

2. Schnermann, J., and Briggs, J. 2000. Function of the juxtaglomerular apparatus: Control of glomerular hemodynamics and renin secretion. In The kidney: physiology and pathophysiology. D.W. Seldin and G. Giebisch, editors. Lippincott Williams \& Wilkins. Philadelphia, Pennsylvania, USA. 945-980.

3. Peti-Peterdi, J., et al. 2003. Luminal $\mathrm{NaCl}$ delivery regulates basolateral $\mathrm{PGE}_{2}$ release from macula densa cells. J. Clin. Invest. 112:76-82. doi:10.1172/ JCI200318018.

4. Paliege, A., et al. 2004. Inhibition of nNOS expression in the macula densa by COX-2-derived prostaglandin $\mathrm{E}_{2}$. Am. J. Physiol. Renal Physiol. 287:F152-F159.

5. Schweda, F., Kammerl, M., Wagner, C., Krämer, B., and Kurtz, A. 2004. Upregulation of macula densa cyclooxygenase-2 expression is not dependent on glomerular filtration. Am. J. Physiol. Renal Physiol. 287:F95-F101.

6. Castrop, H., et al. 2004. Impairment of tubuloglomerular feedback regulation of GFR in ecto-5'nucleotidase/CD73-deficient mice. J. Clin. Invest. 114:634-642. doi:10.1172/JCI200421851.

7. Schnermann, J. 2002. Adenosine mediates tubuloglomerular feedback. Am. J. Physiol. Regul. Integr. Comp. Physiol. 283:R276-R277; discussion R278-R279.

8. Nishiyama, A., and Navar, L. 2002. ATP mediates tubuloglomerular feedback. Am. J. Physiol. Regul. Integr. Comp. Physiol. 283:R273-R275; discussion R278-R279.

9. Osswald, H., Hermes, H., and Nabakowski, G. 1982. Role of adenosine in signal transmission of tubuloglomerular feedback. Kidney Int. Suppl. 12:S136-S142.

10. Osswald, H., Nabakowski, G., and Hermes, H. 1980. Adenosine as a possible mediator of metabolic control of glomerular filtration rate. Int. J. Biochem. 12:263-267.

11. Schnermann, J., Weihprecht, H., and Briggs, J. 1990.
Inhibition of tubuloglomerular feedback during adenosine 1 receptor blockade. Am. J. Physiol. Renal Physiol. 258:F553-F561.

12. Hansen, P., Castrop, H., Briggs, J., and Schnermann, J. 2003. Adenosine induces vasoconstriction through Gi-dependent activation of phospholipase $\mathrm{C}$ in isolated perfused afferent arterioles of mice. J. Am. Soc. Nephrol. 14:2457-2465.

13. Brown, R., et al. 2001. Abolished tubuloglomerular feedback and increased plasma renin in adenosine $A$ 1 receptor-deficient mice. Am. J. Physiol. Regul. Integr. Comp. Physiol. 281:R1362-R1367.

14. Sun, D., et al. 2001. Mediation of tubuloglomerular feedback by adenosine: Evidence from mice lacking adenosine 1 receptors. Proc. Natl. Acad. Sci. U. S. A. 98:9983-9988.

15. Inscho, E., Cook, A., and Navar, L. 1996. Pressuremediated vasoconstriction of juxtamedullary afferent arterioles involves P2-purinoceptor activation. Am. J. Physiol. 271:F1077-F1085.

16. Inscho, E. 2001. P2 receptors in regulation of renal microvascular function. Am. J. Physiol. Renal Physiol. 280:F927-F944.

17. Inscho, E.W., Cook, A.K., Imig, J.D., Vial, C., and Evans, R.J. 2003. Physiological role for $\mathrm{P}_{2} \mathrm{X}_{1}$ receptors in renal microvascular autoregulatory behavior. J. Clin. Invest. 112:1895-1905. doi:10.1172/JCI200318499.

18. Bell, P., et al. 2003. Macula densa cell signaling involves ATP release through a maxi anion channel. Proc. Natl. Acad. Sci. U. S. A. 100:4322-4327.

19. Le Hir, M., and Kaissling, B. 1993. Distribution and regulation of renal ecto-5'-nucleotidase: implications for physiological functions of adenosine. Am. J. Physiol. 264:F377-F387.

20. Thomson, S., Bao, D., Deng, A., and Vallon, V. 2000. Adenosine formed by 5 '-nucleotidase mediates tubuloglomerular feedback. J. Clin. Invest. 106:289-298.

21. Zimmermann, H. 2000. Extracellular metabolism of ATP and other nucleotides. Naunyn Schmiedebergs Arch. Pharmacol. 362:299-309.

\title{
Why does diabetes increase atherosclerosis? I don't know!
}

\author{
Ira J. Goldberg \\ Department of Medicine, Columbia University College of Physicians and Surgeons, New York, New York, USA.
}

\begin{abstract}
There is a wealth of clinical data showing the relationship between diabetes mellitus and atherosclerosis and its clinical complications. To dissect this relationship, investigators have attempted, usually unsuccessfully, to create a small-animal model in which diabetes accelerates vascular lesion development. This effort has often been complicated by development of hyperlipidemia leading to difficulty in differentiating the effects of hyperglycemia from those of lipid abnormalities. A study in the current issue of the JCI provides data on a new mouse model in which atherosclerosis initiation is accelerated in diabetic mice and is reduced by insulin therapy. Moreover, these animals have greater intra-arterial hemorrhage, which might be due to less stable plaques (see the related article beginning on page 659).
\end{abstract}

Nonstandard abbreviations used: AGE, advanced glycation end-product.

Conflict of interest: The author has declared that no conflict of interest exists.

Citation for this article: J. Clin. Invest. 114:613-615 (2004). doi:10.1172/JCI200422826.
Epidemiological data has firmly established the correlation between coronary heart disease and both type 1 and type 2 diabetes mellitus. Is the acceleration of atherosclerosis with insulin deficiency and insulin resistance due to defective insulin actions, hyperglycemia, or some other process that is present in diabetic patients? Several major glucose-lowering trials in type 1 (1) and type 2 diabetic (2) patients that showed reductions in microvascular complications failed to achieve significant reduction in macrovascular events. One hypothesis to explain these trial results is that metabolic abnormalities associated with diabetes, and not overt hyperglycemia per se, accelerate macrovascular complications. Support for this comes from the observation that coronary heart disease is increased in prediabetic patients (3): people who have several metabolic abnormalities associated with type 2 diabetes but who do not have fasting hyperglycemia or elevated glycosylated hemoglobin. Another possibility is that 


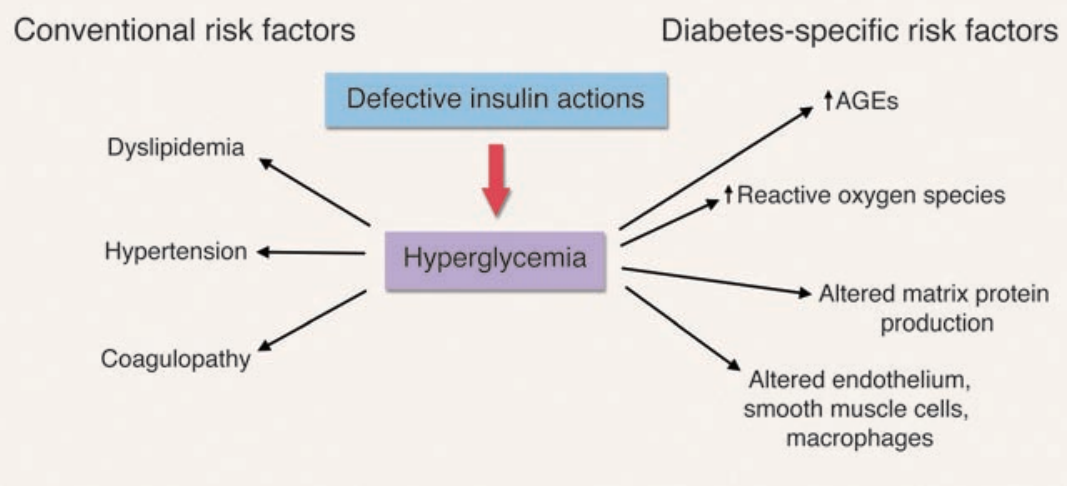

\section{Figure 1}

Potential causes of diabetes-induced macrovascular disease. The presence of increased conventional risk factors in patients with diabetes is surely one reason for greater atherosclerosis (18). In some animal models, diabetes-induced hyperlipidemia occurs and may mask toxic effects of hyperglycemia that confer diabetes-specific risk. Among these effects may be the development of increased levels of AGEs, toxic intracellular reactions to glucose secondary to the production of increased reactive oxygen species (19), and multiple effects on the production of matrix proteins and the biology of cells within the vessel wall.

the clinical trials were insufficient in intensity or duration to have an impact on the disease process in subjects with multiple risk factors. Recently, a 6-year follow-up study showed that type 1 patients receiving more intensive insulin therapy had significantly fewer coronary artery calcifications assessed by electron beam CAT scan and carotid artery intimal/media thickness (4). Thus, as has been surmised for many years, the degree of hyperglycemia has an impact on arterial, as well as capillary, pathology. Cellular and animal experimentation has been used to study the mechanisms linking diabetes and atherogenesis; however, our understanding of diabetes-induced accelerated vascular disease is still incomplete. Diabetes-specific and more general causes of atherosclerosis are shown in Figure 1.

\section{Animal models of diabetes and atherosclerosis}

For more than fifty years, researchers have attempted to create an animal model in which the human association of diabetes and accelerated atherosclerosis is reproduced. Administration of alloxan induced diabetes in rabbits; however, when these rabbits were fed an atherosclerosis-inducing high cholesterol diet, the effect on the diabetes was the opposite of what was expected. Diabetic rabbits had less atherosclerosis than the non-diabetic animals (5). Eventually the results of this experiment were understood when it was discovered that the large, lipid-rich particles produced by the intestines of the diabetic rabbits were unable to penetrate the vascular wall and provide the lipid environment needed to initiate the atherosclerotic process (6). Therefore, even if diabetes promotes inflammation, without vascular lipid deposition, there is no atherosclerosis.

\section{Mouse models of diabetic macrovascular disease}

Although the literature is not lacking in papers showing in vitro and in vivo effects of hyperglycemia that are thought to be deleterious, studies showing direct effects of hyperglycemia on either the quantity or quality of animal atherosclerosis are limited. Mice can be made hyperglycemic. They develop advanced glycation end-products (AGEs) and have receptors that interact with these glucose-modified proteins. Both insulin resistance and insulin deficiency can be produced in the mouse. However, macrovascular complications is uncertain. For this reason, developing mouse models of diabetes-accelerated atherosclerosis is the focus of a current NIH-funded program (see http://www.amdcc.org/).

Diabetes accelerates atherosclerosis in a number of atherosclerotic-prone mice strains, but in many of these models the diabetes also causes greater hyperlipidemia (7-10). In contrast, diabetes without greater hyperlipidemia did not increase atherosclerosis in LDL receptor-knockout (11, 12) and apoB-transgenic $(8,13)$ mice. Thus, the independent effect of hyperglycemia on vascular lesions in the mouse, if it does the impact of hyperglycemia on diabetic occur, has not been shown. In an early study, diabetes increased vascular smoothmuscle cell proliferation, perhaps a harbinger of atherosclerosis, but only in one strain of mice (14).

Could it be that the models used to create diabetes were inappropriate? Maybe the mouse is genetically resistant to diabetes-induced macrovascular complications. Despite more than a decade of research using this model, mouse atherosclerosis might be dissimilar enough from human disease that it is not altered by the same stimuli.

Many animal models of diabetic complications have used either chemical destruction of islets with streptozotocin or genetic modifications, such as loss of leptin actions. Although both models are useful, there is always uncertainty as to whether other systemic effects could occur. Most recently, for example, loss of leptin action in $\mathrm{db} / \mathrm{db}$ mice, which have a defect in leptin receptors, was associated with decreased restenosis in a vascular injury model (15). This experiment suggested that the $\mathrm{db} / \mathrm{db}$ model reflects effects of leptin on the vasculature that are independent of diabetes.

\section{A new model of murine diabetic macrovascular disease}

The paper by Renard et al. in this issue of the JCI is one of the few that contain data showing direct macrovascular effects of diabetes (16). Diabetes was created in LDL receptor-knockout mice using viralinduced autoimmune destruction of the pancreatic islet cells. The diabetic mice had greater atherosclerosis when fed the lowcholesterol diet. In an effort to verify that this increase in early lesions resulted from diabetes and not an associated toxic effect of viral destruction of islets, Renard et al. treated mice with insulin. This corrected the hyperglycemia and insulin deficiency and reduced the size of early lesions in chow-fed mice. Thus, lesion initiation was clearly increased by induction of diabetes.

Does the diabetes also alter more advanced and more human-like lesions in this model? Although diabetic mice fed a cholesterol-containing diet had greater lesion size, the effects of the diabetes exclusive of lipid abnormalities were less apparent (12). This was because, as in several previous models, the diabetic mice had more severe hyperlipidemia. When one compares lesion size in control and diabetic mice with similar cholesterol levels, effects other than the hyperlipidemia are no longer apparent. 
Why is this? Although measurements of lesion area might have reached a plateau, this did not appear to be the case. Perhaps, the toxic effects of severe hyperlipidemia overwhelmed the other effects of diabetes. A similar situation might exist in some human populations in which the development of vascular events is more correlated with lipid profiles (increased LDL and reduced HDL) than glucose control as measured by hemoglobin A1C (17).

Advanced lesions in the diabetic mice had greater amounts of arterial hemorrhage (16). A common final event leading to myocardial infarction in humans is the rupture of a plaque, followed by arterial thrombosis. It is unclear whether similar unstable lesions can be created in mice. Perhaps the intra-arterial bleeding found by Renard et al. was due to plaque rupture even though the vascular wall disruption was not apparent on pathological examination. Other possibilities are that vessels from diabetic mice are more friable or their blood is less able to clot. Whether the formation of lesions in mice is comparable to processes in humans is not yet clear.

\section{Is there something missing in the diabetic mouse?}

Renard et al. have used a nonchemical method to produce a mouse model of insulin-deficient diabetes (16). This model is associated with larger vascular lesions in mice on chow diets and suggests that diabetes increases lesion initiation. In addition, the investigators have described a novel pathological observation, greater hemorrhage into advanced lesions. Unfortunately, we are still lacking a model in which diabetes, either due to insulin resistance or insulin deficiency, uniformly accelerates development of more advanced lesions exclusive of hyperlipidemia. Since mice develop hyperglycemia, it may be that the mouse is genetically unable to mount a human-like response to the toxic effects of glucose. Identification of factors responsible for this might allow development of methods to make humans more mouselike and thus less likely to develop diabetic macrovascular complications.

Address correspondence to: Ira J. Goldberg, Department of Medicine, Columbia University College of Physicians and Surgeons, 630 West 168th Street, New York, New York 10032, USA. Phone: (212) 305-5961; Fax: (212) 305-5484; E-mail: ijg3@columbia.edu.

1. [Anonymous]. 1995. Effect of intensive diabetes management on macrovascular events and risk factors in the Diabetes Control and Complications Trial. Am. J. Cardiol. 75:894-903.

2. UK Prospective Diabetes Study (UKPDS) Group. 1998. Intensive blood-glucose control with sulphonylureas or insulin compared with conventional treatment and risk of complications in patients with type 2 diabetes (UKPDS 33). Lancet. 352:837-853.

3. Haffner, S.M., Mykkanen, L., Festa, A., Burke, J.P., and Stern, M.P. 2000. Insulin-resistant prediabetic subjects have more atherogenic risk factors than insulin-sensitive prediabetic subjects: implications for preventing coronary heart disease during the prediabetic state. Circulation. 101:975-980.

4. Nathan, D.M., et al. 2003. Intensive diabetes therapy and carotid intima-media thickness in type 1 diabetes mellitus. N. Engl. J. Med. 348:2294-2303.

5. Duff, G.L., Brechin, D.J., and Finkelstein, W.E. 1954. The effect of alloxan diabetes on experimental cholesterol atherosclerosis in the rabbit. IV. The effect of insulin therapy on the inhibition of atherosclerosis in the alloxan-diabetic rabbit. J. Exp. Med. 100:371-380.

6. Nordestgaard, B.G., and Zilversmit, D.B. 1988. Large lipoproteins are excluded from the arterial wall in diabetic cholesterol-fed rabbits. J. Lipid Res. 29:1491-1500.

7. Park, L., et al. 1998. Suppression of accelerated diabetic atherosclerosis by the soluble receptor for advanced glycation endproducts. Nat. Med.
4:1025-1031.

8. Kako, Y., Masse, M., Huang, L.S., Tall, A.R., and Goldberg, I.J. 2002. Lipoprotein lipase deficiency and CETP in streptozotocin-treated apoB- expressing mice. J. Lipid Res. 43:872-877.

9. Keren, P., et al. 2000. Effect of hyperglycemia and hyperlipidemia on atherosclerosis in LDL receptordeficient mice: establishment of a combined model and association with heat shock protein $65 \mathrm{immu}$ nity. Diabetes. 49:1064-1069.

10. Hasty, A.H., et al. 2001. Severe hypercholesterolemia, hypertriglyceridemia, and atherosclerosis in mice lacking both leptin and the low density lipoprotein receptor. J. Biol. Chem. 276:37402-37408.

11. Merat, S., Casanada, F., Sutphin, M., Palinski, W., and Reaven, P.D. 1999. Western-type diets induce insulin resistance and hyperinsulinemia in LDL receptor-deficient mice but do not increase aortic atherosclerosis compared with normoinsulinemic mice in which similar plasma cholesterol levels are achieved by a fructose-rich diet. Arterioscler. Thromb. Vasc. Biol. 19:1223-1230.

12. Reaven, P., Merat, S., Casanada, F., Sutphin, M., and Palinski, W. 1997. Effect of streptozotocininduced hyperglycemia on lipid profiles, formation of advanced glycation endproducts in lesions, and extent of atherosclerosis in LDL receptor-deficient mice. Arterioscler. Thromb. Vasc. Biol. 17:2250-2256.

13. Kako, Y., et al. 1999. Streptozotocin-induced diabetes in human apolipoprotein B transgenic mice. Effects on lipoproteins and atherosclerosis. J. Lipid. Res. 40:2185-2194.

14. Kunjathoor, V.V., Wilson, D.L., and LeBoeuf, R.C. 1996. Increased atherosclerosis in streptozotocininduced diabetic mice. J. Clin. Invest. 97:1767-1773.

15. Stephenson, K., et al. 2003. Neointimal formation after endovascular arterial injury is markedly attenuated in $\mathrm{db} / \mathrm{db}$ mice. Arterioscler. Thromb. Vasc. Biol. 23:2027-2033

16. Renard, C., et al. 2004. Diabetes and diabetes-associated lipid abnormalities have distinct effects on initiation and progression of atherosclerotic lesions. J. Clin. Invest. 114:659-668. doi:10.1172/ JCI200417867.

17. Turner, R.C., et al. 1998. Risk factors for coronary artery disease in non-insulin dependent diabetes mellitus: United Kingdom Prospective Diabetes Study (UKPDS: 23). BMJ. 316:823-828.

18. Grundy, S.M., et al. 1999. Diabetes and cardiovascular disease: a statement for healthcare professionals from the American Heart Association. Circulation. 100:1134-1146.

19. Brownlee, M. 2001. Biochemistry and molecular cell biology of diabetic complications. Nature. 414:813-820. 